\title{
Noble Gas (Argon and Xenon)-Saturated Cold Storage Solutions Reduce Ischemia- Reperfusion Injury in a Rat Model of Renal Transplantation
}

\author{
Y. Irani ${ }^{a, c} \quad$ J.L. Pype ${ }^{g} \quad$ A.R. Marting $\quad$ C.F. Chong ${ }^{g} \quad$ L. Daniel $^{\mathrm{d}}$ \\ J. Gaudart $\quad$ Z. Ibrahim ${ }^{f} \quad$ G. Magalon ${ }^{a, c} \quad$ M. Lemaire ${ }^{g}$ \\ J. Hardwigsen ${ }^{b}$
}

Departments of a Plastic and Reconstructive Surgery and ${ }^{b}$ General Surgery and Liver Transplantation, Hospital CHU Conception, 'Experimental Microsurgery Research Unit, Timone Medicine Faculty, and Departments of ${ }^{\mathrm{d} P a t h o l o g y,}{ }^{\mathrm{e} B i o m a t h e m a t i c s, ~ a n d ~}$ fBiochemistry, Hospital CHU Timone, Marseille, and ${ }^{9}$ Air Liquide R\&D Medical Gases Group, Air Liquide Sante International - Claude Delorme Research Center, Jouy-en-Josas, France

\section{Key Words}

Argon $\cdot$ Xenon $\cdot$ Transplantation $\cdot$ Kidney $\cdot$ Organ-protection $\cdot$ Ischemia-reperfusion injury • Storage

\begin{abstract}
Background: Following kidney transplantation, ischemia-reperfusion injury contributes to adverse outcomes. The purpose of this study was to determine whether a cold-storage solution saturated with noble gas (xenon or argon) could limit ischemia-reperfusion injury following cold ischemia. Methods: Sixty Wistar rats were randomly allocated to 4 experimental groups. Kidneys were harvested and then stored for $6 \mathrm{~h}$ before transplantation in cold-storage solution $\left(\right.$ Celsior $\left.{ }^{\circledR}\right)$ saturated with either air, nitrogen, xenon or argon. A syngenic orthotopic transplantation was performed. Renal function was determined on days 7 and 14 after transplantation. Transplanted kidneys were removed on day 14 for histological and immunohistochemical analyses. Results: Creatinine clearance was significantly higher and urinary albumin significantly lower in the argon and xenon groups than in the other groups at days 7 and 14. These effects were considerably more pronounced for argon than for xenon. In addition, kidneys stored with argon, and to a lesser extent those stored with xenon, displayed preserved renal architecture as
\end{abstract}


well as higher CD-10 and little active caspase-3 expression compared to other groups. Conclusion: Argon- or xenon-satured cold-storage solution preserved renal architecture and function following transplantation by reducing ischemia-reperfusion injury.

Copyright $\odot 2012$ S. Karger AG, Basel

\section{Introduction}

Renal transplantation is one of the three methods of renal replacement therapy (along with hemodialysis and peritoneal dialysis) for end-stage renal disease. However, this therapeutic option is limited due to the shortage of organs available for transplantation. The waiting list for kidney transplants in the United States reached more than 85,595 patients in 2010 despite the increasing number of renal grafts performed each year $(13,620$ in $2000,16,829$ in 2009) [1].

The shortage of renal grafts is largely due to the shortage of suitable donors. Deceased donors account for more than $60 \%$ of all donor types in the United States [2]. The recovered organs often have to be transported over a long distance in order to reach the best recipient, thus the length of preservation needs to be increased [3].

The objective of organ preservation is to preserve viability as long as possible with minimum organ damage. With current preservation techniques, a prolonged renal ischemia $(>20 \mathrm{~h})$ increases morbidity and delayed graft function [4]. The latter is correlated with a poor long-term survival of renal grafts [5]. However, a longer preservation time is mandatory in order to increase the donor pool and to provide adequate time for graft assessment.

During organ preservation, the graft should be protected against both short-term (acute tubular necrosis , ATN) and long-term (chronic nephropathy of the graft) adverse outcomes [6]. Organ damage will occur during cold ischemia preservation and will worsen after reperfusion. The ex vivo preserved organ will display an anaerobic metabolism and produce a massive amount of reactive oxygen species (ROS) upon reperfusion, which are correlated with ischemia-reperfusion injury [6-8]. Cold-storage techniques were developed in order to reduce ROS induction and these techniques have contributed to major improvement in renal transplantation over the last few decades. However, in the past few years, this progress has stalled. Recent studies, based on important cohorts, show equivalence between many of the newer solutions [6].

Xenon and argon are both noble gases with biological effects. Xenon is currently marketed in Europe as an anesthetic agent, with demonstrated neuroprotective [9-13] and organ-protective [14-18] effects. Argon has no anesthetic properties under normobaric conditions [19] and its possible effects on cell protection have not been studied to the same extent as those of xenon. Argon has been found to protect hypoxia-, cisplatin- and gentamycinexposed hair cells in the newborn rat's organ of Corti [20]. More recently, argon has been shown to have neuroprotective properties, as demonstrated in an in vitro model of neuronal injury [21]. Further studies in in vitro models of ischemia and traumatic brain injury demonstrated that argon exerted an effective neuroprotective potential; in these studies, argonmediated protection was observed at several concentrations, either directly applied after trauma or when administered 2-3 h after injury [22].

The present study was designed to evaluate the effects of organ preservation in coldstorage solutions containing dissolved noble gases (xenon or argon), compared to dissolved nitrogen or air, in a rat model of renal transplantation. 


\section{Materials and Methods}

This study was approved by the University of Timone Committee on Use and Care of Animals (UCTCA). All rats received humane care in compliance with the Guide for the Care and Use of Laboratory Animals.

\section{Experimental Design}

Using a standard rat model of transplantation, kidneys were removed, stored for $6 \mathrm{~h}$ cold ischemia, and transplanted into nephrectomized rat recipients. Prior to storage, cold storage solution was saturated with air, nitrogen, xenon, or argon. Kidneys preserved in air served as the control group. Renal function was assessed at 7 and 14 days after transplantation, while histological and immunohistochemical analysis were performed on day 14 .

\section{Animal Model}

The following model was used in all experiments. 120 male inbred Wistar rats (Charles River, St Germain sur l'Arbresle, France), weighing between 200 and 250 g were used as donors and recipients. Anesthesia was induced by inhalation of $3 \%$ isoflurane (Forène ${ }^{\circledR}$; Abbott France, Rungis, France). A piece of gauze was put in the bottom of a glass chamber, and $5 \mathrm{ml}$ of isoflurane were dispensed on the gauze. Induction of anesthesia was achieved by placing the rat in the chamber for 1-2 min. The rat was weighed. Anesthesia was maintained by inhalation of mixed gases: isoflurane $(1.5 \%)+\mathrm{N}_{2} \mathrm{O}$ (2 liters/min; AGA Medical, Rueil-Malmaison, France) $+\mathrm{O}_{2}$ (1.5 liters/min; AGA Medical). Analgesia was obtained by injecting subcutaneously $5 \mathrm{mg} / \mathrm{kg}$ of morphine chlorhydrate (Aguettant ${ }^{\circledR}$, Lyon, France). The rat was kept under spontaneous breathing. The amount of isoflurane was adapted when needed. Rats were heated using a hot pad. At the end of the surgical intervention and prior to baseline data collection, a 24-hour acclimation period was allowed for all animals.

\section{Donor Model}

2,000 IU/kg Heparin Sodium (Panpharma, Fougères, France) was administered 5 min before proximal ligation of the renal artery. A midline laparotomy was performed. The left kidney was chosen for transplantation because of the length of the vessels and its more caudal position. The bowel was covered with moist gauze and retracted to the right. The vessels were identified and the surrounding soft tissue was dissected. The left kidney was perfused with $10 \mathrm{ml}$ of ice-cold Celsior ${ }^{\circledR}$ solution containing 500 units of heparin at $3 \mathrm{ml} / \mathrm{min}$ until the kidney became uniformly pale and effluent clear. Flushing of the graft was handmade. The pressure applied on the syringe was minimal by applying a flow of about $3 \mathrm{ml} / \mathrm{min}$ to avoid injury to the graft. This was followed by rapid removal of the renal graft, after which the rats were euthanized.

\section{Kidney Preservation}

Grafts were weighed and placed into $200 \mathrm{ml}$ of $4{ }^{\circ} \mathrm{C}$ gas-saturated Celsior ${ }^{\circledR}$ solution, which was prepared according to the following procedure: Celsior ${ }^{\circledR}$ solution was cooled to $4^{\circ} \mathrm{C}$ and poured into a gas-tight bottle, the lid of which contained a gas inlet and outlet, and a connection to an external manometer (PR205; Eurolec, Dundalk, Ireland) used to monitor the pressure inside the bottle. As shown schematically in figure 1, the gas inlet connected to a tube inside the bottle which extended below the liquid level so that input gas bubbled through the solution. In addition, gas-tight valves were placed at all 3 connections to the bottle lid, so as to seal the bottle contents from the outside environment after the preparation period. 
Fig. 1. Schematic of the apparatus used to prepare gas-saturated preservation solution.

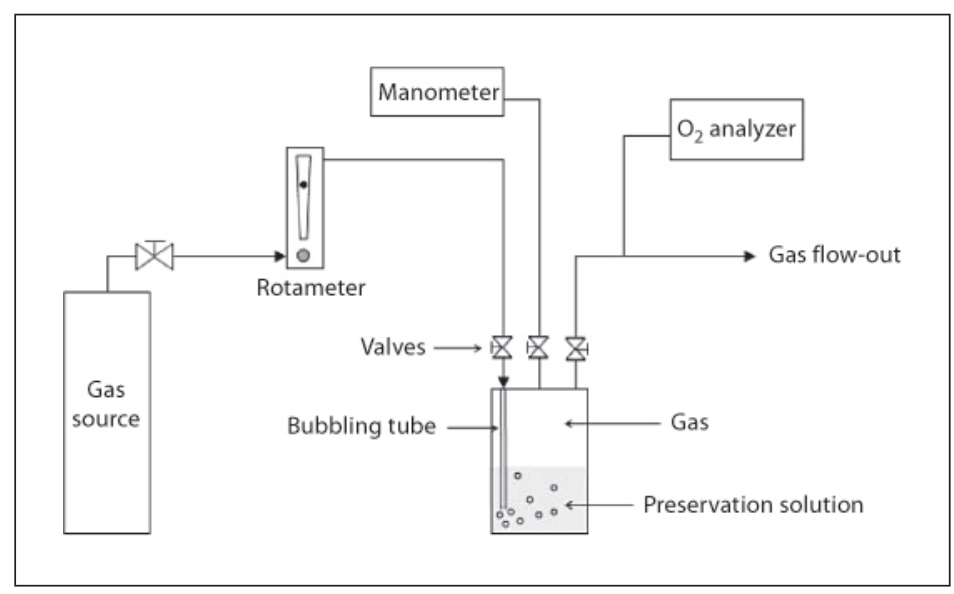

To prepare the solution, gas was supplied to the bottle at 2 liters/min until the oxygen concentration monitored at the outlet reached zero percent. Gas flow rates were adjusted and monitored using an inline rotameter calibrated for air (0.4-5 LPM Air; Cole Parmer, Vernon Hills, Ill., USA), with appropriate correction factors applied for the other gases. Oxygen concentrations were measured using an electrochemical cell (Oxybaby 5.0; Wittgas, Witten, Germany). To ensure saturation of the solution prior to introduction of the kidney, all 3 valves were closed, and the solution was maintained under a positive gas pressure of 200 mbar at $4^{\circ} \mathrm{C}$ for $12-24 \mathrm{~h}$. After this pre-saturation period, the bottle was opened, and the kidney was placed in solution. The bottle was then closed, and the above procedure was repeated with the bubbling tube removed, so as to again ensure the solution was kept under a pure gas atmosphere. The kidney was then stored in solution for $6 \mathrm{~h}$ at $4{ }^{\circ} \mathrm{C}$.

\section{Recipient Model}

Healthy rats underwent similar surgical intervention as described for the donor rats, with additional bilateral nephrectomy. Before transplantation, recipients were housed in metabolic cages for $24 \mathrm{~h}$ to collect urine and blood samples $(600 \mu \mathrm{l})$ from the tail vein, to obtain baseline biochemical values. The graft was weighed after preservation. Warm ischemic time and ureteral suture time were monitored. After removal of the left kidney, the donor kidney was implanted and the remaining (i.e. right) kidney was removed. The left renal vein and artery were prepared for end-to-end vascular anastomosis of the experimental graft. The ureter was also prepared for end-to-end anastomosis to allow natural urine output collection.

After surgery, rats were housed individually. Pelleted food and water was available at all times. The analgesic buprenorphine $\left(0.15 \mathrm{mg} / \mathrm{kg}\right.$, Temgésic ${ }^{\circledR}$; Schering-Plough, LevalloisPerret, France) was administered in drinking water every day for a period of 3 days. At days 7 and 14, rats were placed in metabolic cages with free access to food and water. Rats were weighed and the 24 -hour urine output was measured and $600 \mu \mathrm{l}$ of blood were drawn from the tail vein.

At day 14, recipient rats again underwent surgical intervention as described above for donor rats. A complete examination of the abdominal cavity was performed in order to look for postoperative adhesion, vascular thrombosis in renal vessels or ureteral stenosis and dilatation above the sutures. The graft was explanted for histological and immunohistochemical analysis. Recipient rats were then euthanatized with $\mathrm{CO}_{2}$ at an initial concentration of $30 \%$, as recommended by the American Veterinary Medical Association on Euthanasia [23]. 
Functional Analysis

Renal function was estimated by creatinine clearance and urinary albumin obtained from the $24 \mathrm{~h}$ urine samples at days 7 and 14 . Delayed graft function was assessed by the creatinine clearance value at days 7 and 14 . Creatinine clearance $(\mathrm{ml} / \mathrm{min})$ was calculated using the following equation: $\mathrm{CrCl}=([\mathrm{U}] \times(\mathrm{UO} / 60)) /[\mathrm{P}]$, in which $[\mathrm{U}]=$ urine concentration of creatinine, $[\mathrm{P}]=$ plasma concentration of creatinine, and $\mathrm{UO}=$ urine output in $\mathrm{ml} / \mathrm{h}$.

\section{Histological and Immunohistochemical Analysis}

Grafts were weighed and cut in blocks. They were fixed by infusion of $4 \%$ buffered formaldehyde for $24 \mathrm{~h}$ and embedded in paraffin. Five micrometer cuts were obtained from the blocks and HES (hematoxylin-eosin-safran) stained, for histological analysis. Immunodetections were performed on $5 \mu \mathrm{m}$-thick serial cryostat sections (cryostat Reichert-Jung $2800^{\mathrm{E}}$; Leica, Rueil-Malmaison, France). The following antibodies were used: anti-active caspase-3 (clone: C92-605; BD Pharmingen, Becton Dickinson France S.A.S. Belgian Branch, Erembodegem, Belgium) and anti-CD10 (clone: 56-C6; Diagnostic Biosystems, Pleasanton, Calif., USA). Normal rat kidneys were used as controls. Negative controls were obtained by omitting the primary antibodies and using irrelevant immunoglobulins or phosphate-buffered saline. After being rinsed, the sections were incubated for $30 \mathrm{~min}$ with biotinylated secondary antibodies and then visualized by avidin-biotin peroxidase (Vectastain kit; Vector, Burlingame, England). The slides were processed and analyzed under blinded conditions by a pathologist.

\section{Statistical Analysis}

Results obtained for kidneys preserved with the different gases were compared. The analysis was performed on 15 rats per group.

Results are expressed as means \pm standard deviation (SD). Statistical significance was assessed by one-way analysis of variance (ANOVA) to determine differences between groups, followed by Newman-Keuls post hoc test. The statistical analysis was carried out with GraphPad Prism software (GraphPad Software Inc., San Diego, Calif., USA). Survival analysis was performed with $\mathrm{R}^{\circledR}$ software $\left(\mathrm{R}^{\circledR}\right.$ Foundation for Statistical Computing, Vienna, Austria) using the Kaplan-Meier estimator and compared with log-rank test. Values of $p<0.05$ were considered statistically significant.

\section{Results}

A significant statistical difference between the 4 groups was found neither in the weight of the donor rats nor in the pre-operative values of creatinine clearance and urinary albumin at day 0 . In addition, neither warm ischemia time nor ureteral suture time were significantly different between groups and no statistical significant difference was found between the groups in the weights of the kidneys before and after storage, suggesting no tissue edema (table 1).

Four rats out of 19 died in the air group, 2 of 17 in the nitrogen group and 1 of 16 in the argon group. All the rats that were treated with xenon survived 2 weeks. These differences were not statistically significant. Deaths may have resulted from microsurgical hazards, although they were not directly attributable to surgical complications, as no sign of vascular thrombosis or ureteral stenosis was found during autopsy of the animals.

\section{Effects of Gases on Renal Function}

No difference was observed between groups in the pre-operative value of creatinine clearance on day 0 ; the average value across all groups was $0.54 \pm 0.07 \mathrm{ml} / \mathrm{min} / 100 \mathrm{~g}$. As displayed in figure 2 , on the 7 th day after transplantation creatinine clearance had declined 
Fig. 2. Creatinine clearance in rats, 7 and 14 days following renal transplantation of kidneys that were stored for $6 \mathrm{~h}$ in air-, nitrogen-, xenon- or argon-saturated Celsior ${ }^{\circledR}$ solution. Data are expressed as mean \pm SEM. ${ }^{* *}$, ${ }^{\# \#}$, or ${ }^{\$ \$}$ signifies a statistically significant difference compared to the air group, the nitrogen group, or the xenon group, respectively $(\mathrm{p}<0.001, \mathrm{n}=15)$.

Fig. 3. The effect of storing rat kidneys for $6 \mathrm{~h}$ in air-, nitrogen-, xenon- or argon-saturated Celsior ${ }^{\circledR}$ solution on urinary albumin, 7 and 14 days after transplantation. Day 0 represents the pre-operative urinary albumin value. Data are expressed as mean $\pm \operatorname{SEM}(\mathrm{n}=15) .{ }^{*}(\mathrm{p}<0.05),{ }^{*}(\mathrm{p}<0.01)$, or *** $(\mathrm{p}<0.001)$ signifies a statistically significant difference compared to the air group; ${ }^{\# \#}(\mathrm{p}<0.01)$,

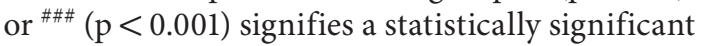
difference compared to the nitrogen group; and $\$ \$(p<0.001)$ signifies a statistically significant difference compared to the xenon group.
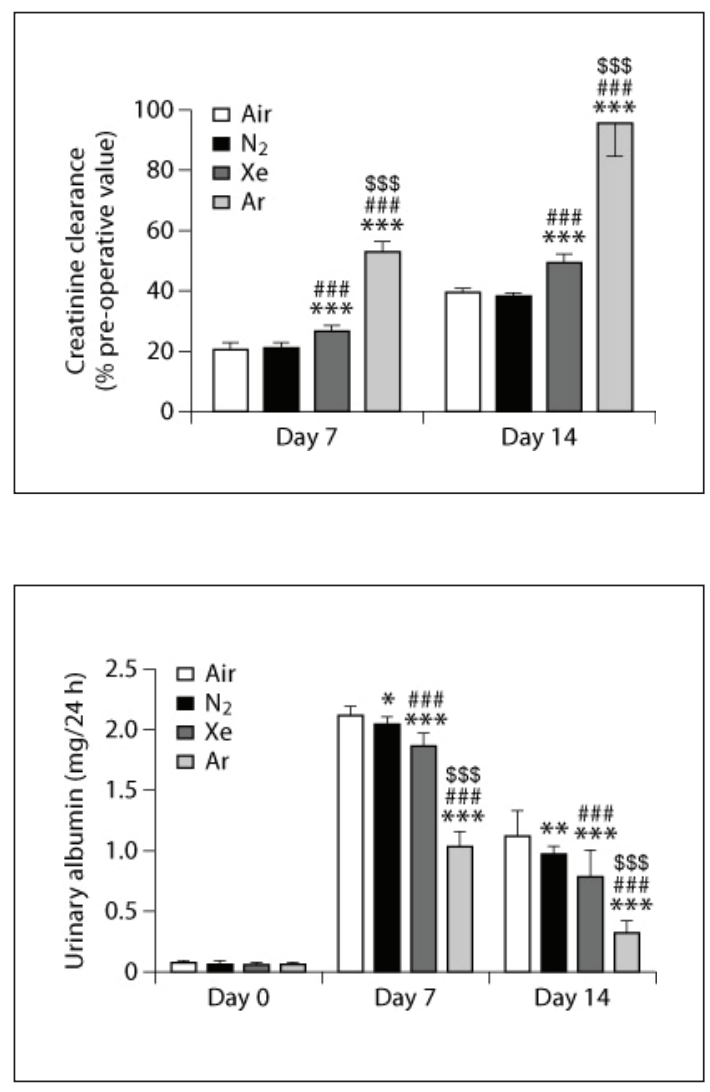

Table 1. Baseline parameters at day 0

\begin{tabular}{lcccc}
\hline & Air & Nitrogen & Xenon & Argon \\
\hline Weight of donor at day 0, g & $225 \pm 14$ & $215 \pm 8$ & $221 \pm 9$ & $223 \pm 11$ \\
Warm ischemia, min & $24.7 \pm 3.2$ & $25.9 \pm 2.7$ & $25.1 \pm 1.9$ & $24.6 \pm 3$ \\
Ureteral suture time, min & $13.6 \pm 4.2$ & $12.9 \pm 4.7$ & $13.0 \pm 3.8$ & $12.0 \pm 3.9$ \\
Weight of the kidney (g) before storage & $1.1 \pm 0.1$ & $1.1 \pm 0.1$ & $1.1 \pm 0.1$ & $1.1 \pm 0.1$ \\
Weight of the kidney after storage, g & $1.4 \pm 0.1$ & $1.3 \pm 0.1$ & $1.3 \pm 0.1$ & $1.2 \pm 0.1$ \\
Creatinine clearance at day 0, $\mathrm{ml} / \mathrm{min} / 100 \mathrm{~g}$ & $0.53 \pm 0.03$ & $0.54 \pm 0.04$ & $0.54 \pm 0.02$ & $0.54 \pm 0.03$ \\
Urinary albumin at day 0, $\mathrm{mg} / 24 \mathrm{~h}$ & $0.07 \pm 0.01$ & $0.07 \pm 0.01$ & $0.06 \pm 0.01$ & $0.06 \pm 0.01$
\end{tabular}

Values are expressed as mean \pm standard deviation $(\mathrm{n}=15)$.

in all groups. Creatinine clearance was significantly greater for the argon group than for all other groups. The creatinine clearance for the xenon group was significantly greater than those for air and nitrogen groups, which did not differ from one another.

Creatinine clearance had increased in all groups by day 14 (fig. 2). Values were still lower than those at day 0 , except for the argon group, which reached $96 \pm 11 \%$ of its preoperative value. For the xenon group, values were significantly greater than those for air and nitrogen, which again did not differ from each other.

Urinary albumin was very low at day 0 (averaging $0.06 \pm 0.01 \mathrm{mg} / 24 \mathrm{~h}$ across all groups), and did not differ between groups. As shown in figure 3 , on the 7 th day after transplantation 

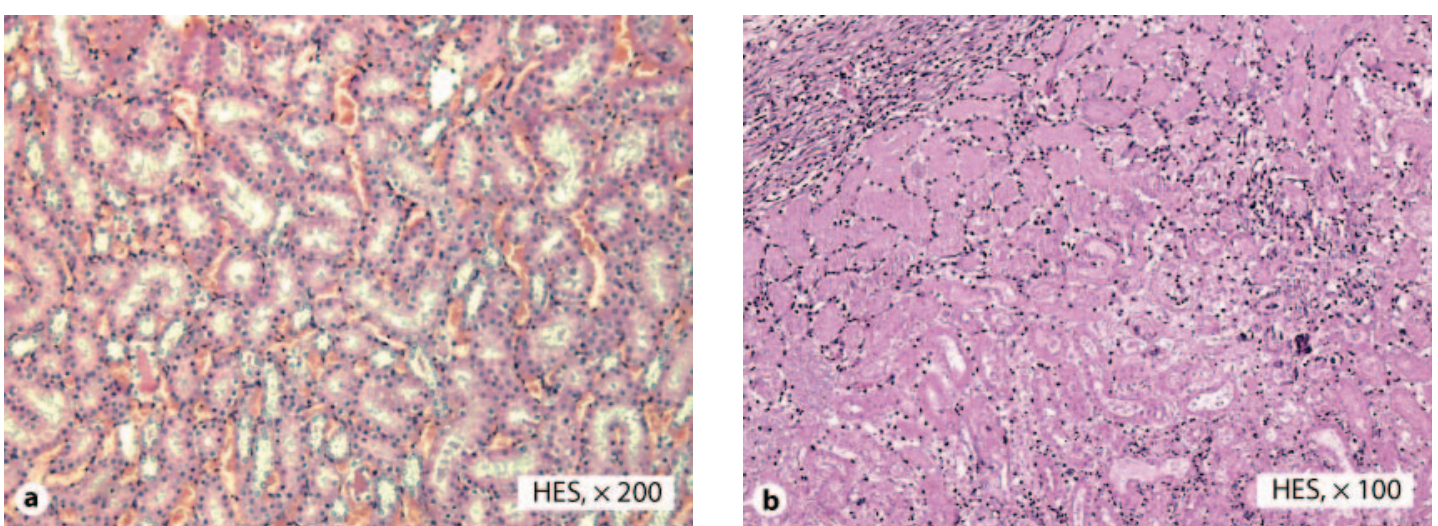

Fig. 4. Microscopic images of rat renal anatomical structures. a Reference kidney, not having undergone any storage period, displaying intact renal architecture with normal tubules. b Kidney stored for $6 \mathrm{~h}$ in air-saturated Celsior ${ }^{\circledR}$ solution, analyzed 14 days after transplantation, demonstrating an area of necrosis. c Kidney stored for $6 \mathrm{~h}$ in argonsaturated Celsior ${ }^{\circledR}$ solution, analyzed 14 days after transplantation, displaying intact renal architecture without significant tubular injuries.

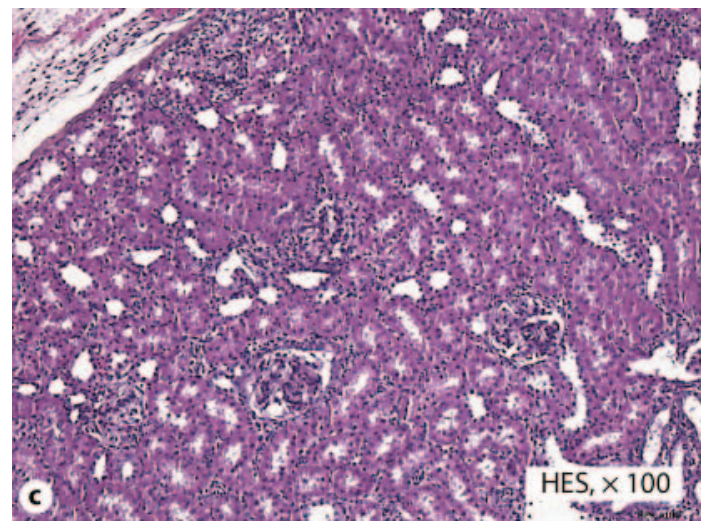

urinary albumin was elevated in all groups, though it was significantly lower for the argon group than for all other groups. Urinary albumin for the xenon group was significantly lower than for the air and nitrogen groups; in turn, that for the nitrogen group was slightly, but significantly, lower than that for air.

Similar to the trend observed for creatinine clearance, values of urinary albumin on day 14 reflected improved renal function compared to day 7 (fig. 3); however, these values remained elevated compared to day 0 . As on day 7 , urinary albumin was significantly lower for the argon group than for the other 3 groups. Urinary albumin for the xenon group was again significantly lower than for the air and nitrogen groups, while that for the nitrogen group was significantly lower than that for air.

\section{Histological Analysis}

Reference kidneys, not having undergone any storage period, displayed intact renal architecture showing normal glomeruli and proximal tubules with intact brush borders (fig. 4a).

As seen in figure $4 \mathrm{~b}$, air group kidneys predominantly displayed focal areas of necrosis (observed in 11 of 15 kidneys). The authors checked for technical failures and none were retrieved.

Five out of 15 nitrogen kidneys displayed focal necrosis, while the remaining grafts displayed wide-spread tubular injuries and local inflammatory lesions.

Six xenon kidneys out of 15 displayed focal necrosis, and 3 displayed ATN lesions. The other 6 grafts displayed local tubular lesions, without modification of the renal architecture.

None of the argon kidneys displayed necrosis. Two displayed ATN injuries, while the other 13 grafts displayed few local inflammatory lesions and few local epithelial lesions (fig. 4c). 

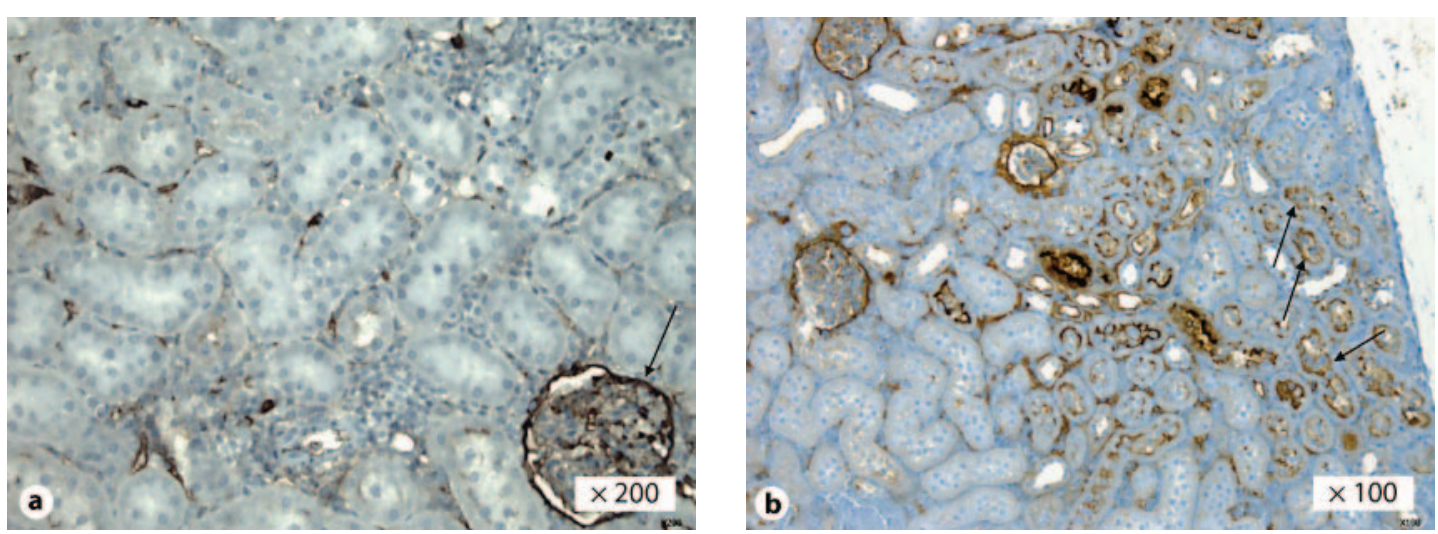

Fig. 5. Expression of CD10 and active caspase- 3 in rat kidneys. Absence (a) and presence (b) of CD10 tubular expression in kidneys stored for $6 \mathrm{~h}$ in airor argon-saturated Celsior ${ }^{\circledR}$ solution, respectively, 14 days after transplantation. Arrows in $\mathbf{b}$ indicate tubular CD10 expression. Note that in a, one glomeruli displays CD10 expression (arrow). Presence of active caspase-3 tubular nuclear expression in kidneys stored for $6 \mathrm{~h}$ in air-saturated Celsior ${ }^{\circledR}$ solution, 14 days after transplantation (c). Arrow in $\mathbf{c}$ indicates active caspase-3 tubular nuclear expression.

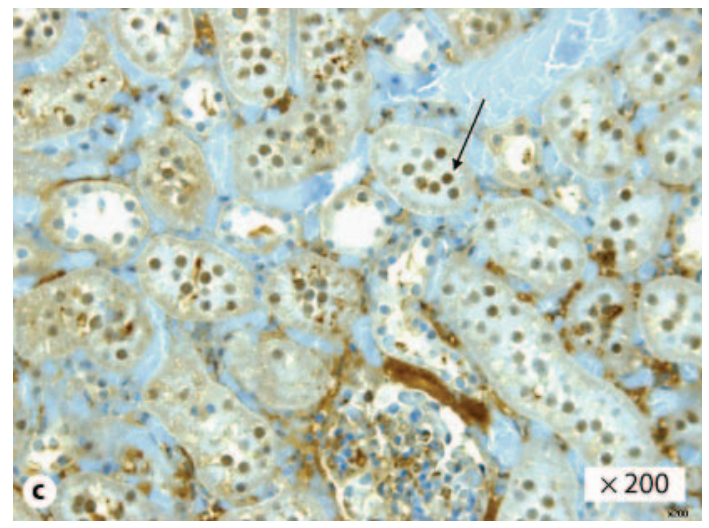

\section{Immunohistochemical Analysis}

In normal kidneys, the parietal epithelium of the Bowman's capsule was immunoreactive with CD10 antibody, indicating intact podocytes. Tubules were also immunoreactive. Normal kidneys were not immunoreactive with active caspase- 3 antibody.

Kidneys that displayed intact renal architecture, mainly seen in the argon group, were immunoreactive with CD10 antibody, whereas the majority of those from the other groups had a loss of tubular CD10 expression, as is shown for a kidney from the air group in figure $5 \mathrm{a}, \mathrm{b}$. Furthermore, the absence of tubular CD10 expression together with the presence of glomeruli CD10 expression in the same tissue slide (fig. 5a) indicates discrete tubular injuries with intact glomeruli.

When necrosis was observed (e.g. in 11 of the 15 kidneys from the air group) there was no or very little active caspase 3 expression, while kidneys with only moderate injury (e.g. the remaining kidneys from the air group) showed high expression of caspase-3 (fig. 5c). Kidneys that displayed intact renal architecture (e.g. the majority of those from the argon group) displayed very local or no active capase-3 expression.

\section{Discussion}

The biochemical results presented above demonstrate that storage of rat kidneys in an argon-saturated solution improved renal function after transplantation, compared to storage in solutions saturated with xenon, nitrogen, or air. In particular, 14 days after transplantation, the creatinine clearance of grafts that had been stored in argon returned nearly to its 
preoperative value. At the same time point, urinary albumin was significantly lower for the argon group than for the other 3 groups. While storage in xenon was also beneficial compared to nitrogen or air, improvements in renal function were less pronounced than those for argon.

The qualitative morphological and immunohistological analyses were consistent with the biochemical results. Grafts stored in argon displayed intact renal architecture 14 days after transplantation, characterized by intact tubules, as well as preserved CD10 expression and only very locally active caspase- 3 expression. CD10 is a protein that is expressed in the brush border of the proximal tubule $[24,25]$ and by the podocytes of the glomerular basement membrane [26]. CD10 is a reflection of tubular injury but it provides a more detailed analysis of tubular injuries than standard microscopy. Decreased CD10 expression is correlated with tubular injury [27].

In peri-tubular cells, expression of active caspase-3, a nuclear marker of apoptosis [28], is associated with tubular injury. As shown previously, active caspase- 3 activity increases in the event of ischemia-reperfusion injury [29] and ATN [30] in animal models of kidney disease. In the present study, kidneys with intact renal architecture displayed no or very low active caspase-3 expression; however, for kidneys with severe injury, displaying massive loss of CD10 expression, active caspase-3 expression was also absent or low. Though this result may seem contradictory, it may be that for severely injured kidneys the apoptotic process had run its course and the tissue was almost entirely necrotic, which would explain the lack of active caspase- 3 expression. Alternatively, primary necrosis may have been the predominant mechanism of cell death.

Given that kidneys stored in solutions saturated with argon or xenon displayed improved renal function after transplantation compared to the nitrogen group, it appears reasonable to conclude that these effects resulted from biological properties of the gases, and not solely from the physical process of removing oxygen from solution, as previously suggested for argon [31]. Indeed, little difference was observed between the nitrogen and air groups. During cold-storage numerous processes, in addition to ischemia, may affect renal function after transplantation as a result of hypothermia, including cell swelling, microtubule disruption, and protein relocalization [32]. This work reports empirical results and the authors are aware of the fact that no mechanisms of action have been investigated yet. Clearly, continued research and follow-up experiments are required in order to elucidate the mechanisms through which argon and xenon help preserve organs. Further, although cell- and organ-protective effects of xenon [9-18] have been more widely reported than those of argon [20-22], it should be noted that in the present study argon proved much more effective than xenon in preserving renal function.

It is important to emphasize that the results presented here were obtained in rat renal grafts, for which viability decreases at a shorter cold-ischemic time period than for human renal grafts. Although this experimental model is in use in preclinical research on renal transplantation, further work should be performed to evaluate whether or not effects are similar in other species and for other organs.

In summary, preservation of rat kidneys in argon or xenon pre-saturated cold-storage solution decreased ischemia-reperfusion injury, improved graft function, and maintained anatomical structure. Accordingly, argon shows considerable potential for improving the quality of grafts used for organ transplantation.

\section{Disclosure Statement}

This study was funded by Air Liquide. 


\section{References}

1 UNOS TOPaTNa: OPTN. Donors recovered in the U.S. Bill donor type. Available at: http://optn. transplant.hrsa.gov. 2010 (accessed 2010 August 12th).

2 IOM: Organ Donation: Opportunities for Action 2006 Edn. Washington, DC, The National Academies Press, 2006.

3 Morris PJ, Johnson RJ, Fuggle SV, Belger MA, Briggs JD: Analysis of factors that affect outcome of primary cadaveric renal transplantation in the UK. HLA Task Force of the Kidney Advisory Group of the United Kingdom Transplant Support Service Authority (UKTSSA). Lancet 1999;354:11471152.

4 Shrestha BM, Haylor JL: Factors influencing long-term outcomes following renal transplantation: a review. JNMA J Nepal Med Assoc 2007;46:136-142.

5 Ojo AO, Wolfe RA, Held PJ, Port FK, Schmouder RL: Delayed graft function: risk factors and implications for renal allograft survival. Transplantation 1997;63:968-974.

6 Badet L, Eugene M, Hauet T, Barrou B: The use of preservation solutions in renal transplantation. Prog Urol 2006;16:25-31.

7 Koyama I, Bulkley GB, Williams GM, Im MJ: The role of oxygen free radicals in mediating the reperfusion injury of cold-preserved ischemic kidneys. Transplantation 1985;40:590-595.

8 Yin M, Currin RT, Peng XX, Mekeel HE, Schoonhoven R, Lemasters JJ: Carolina rinse solution minimizes kidney injury and improves graft function and survival after prolonged cold ischemia. Transplantation 2002;73:1410-1420.

9 Ma D, Wilhelm S, Maze M, Franks NP: Neuroprotective and neurotoxic properties of the 'inert' gas, xenon. Br J Anaesth 2002;89:739-746.

10 Wilhelm S, Ma D, Maze M, Franks NP: Effects of xenon on in vitro and in vivo models of neuronal injury. Anesthesiology 2002;96:1485-1491.

11 Ma D, Yang H, Lynch J, Franks NP, Maze M, Grocott HP: Xenon attenuates cardiopulmonary bypassinduced neurologic and neurocognitive dysfunction in the rat. Anesthesiology 2003;98:690-698.

12 Homi HM, Yokoo N, Ma D, Warner DS, Franks NP, Maze M, et al: The neuroprotective effect of xenon administration during transient middle cerebral artery occlusion in mice. Anesthesiology 2003; 99:876-881.

13 Petzelt C, Blom P, Schmehl W, Muller J, Kox WJ: Prevention of neurotoxicity in hypoxic cortical neurons by the noble gas xenon. Life Sci 2003;72:1909-1918.

14 Weber NC, Frassdorf J, Ratajczak C, Grueber Y, Schlack W, Hollmann MW, et al: Xenon induces late cardiac preconditioning in vivo: a role for cyclooxygenase 2? Anesth Analg 2008;107:1807-1813.

15 Ma D, Lim T, Xu J, Tang H, Wan Y, Zhao H, et al: Xenon preconditioning protects against renal ischemic-reperfusion injury via HIF-1alpha activation. J Am Soc Nephrol 2009;20:713-720.

16 Weber NC, Toma O, Wolter JI, Obal D, Mullenheim J, Preckel B, et al: The noble gas xenon induces pharmacological preconditioning in the rat heart in vivo via induction of PKC-epsilon and p38 MAPK. Br J Pharmacol 2005;144:123-132.

17 Preckel B, Mullenheim J, Moloschavij A, Thamer V, Schlack W: Xenon administration during early reperfusion reduces infarct size after regional ischemia in the rabbit heart in vivo. Anesth Analg 2000;91:1327-1332.

18 Reinelt H, Marx T, Kotzerke J, Topalidis P, Luederwald S, Armbruster S, et al: Hepatic function during xenon anesthesia in pigs. Acta Anaesthesiol Scand 2002;46:713-716.

19 Koblin DD, Fang Z, Eger EI 2nd, Laster MJ, Gong D, Ionescu P, et al: Minimum alveolar concentrations of noble gases, nitrogen, and sulfur hexafluoride in rats: helium and neon as nonimmobilizers (nonanesthetics). Anesth Analg 1998;87:419-424.

20 Yarin YM, Amarjargal N, Fuchs J, Haupt H, Mazurek B, Morozova SV, et al: Argon protects hypoxia-, cisplatin- and gentamycin-exposed hair cells in the newborn rat's organ of Corti. Hear Res 2005;201: $1-9$.

21 Jawad N, Rizvi M, Gu J, Adeyi O, Tao G, Maze M, et al: Neuroprotection (and lack of neuroprotection) afforded by a series of noble gases in an in vitro model of neuronal injury. Neurosci Lett 2009; 460:232-236.

22 Loetscher PD, Rossaint J, Rossaint R, Weis J, Fries M, Fahlenkamp A, et al: Argon: neuroprotection in in vitro models of cerebral ischemia and traumatic brain injury. Crit Care 2009;13:R206.

232000 Report of the AVMA Panel on Euthanasia: J Am Vet Med Assoc 2001; 218: 669-696. 
24 Avery AK, Beckstead J, Renshaw AA, Corless CL: Use of antibodies to RCC and CD10 in the differential diagnosis of renal neoplasms. Am J Surg Pathol 2000;24:203-210.

25 Chu P, Arber DA: Paraffin-section detection of CD10 in 505 nonhematopoietic neoplasms. Frequent expression in renal cell carcinoma and endometrial stromal sarcoma. Am J Clin Pathol 2000;113: 374-382.

26 Smeets B, Te Loeke NA, Dijkman HB, Steenbergen ML, Lensen JF, Begieneman MP, et al: The parietal epithelial cell: a key player in the pathogenesis of focal segmental glomerulosclerosis in Thy-1.1 transgenic mice. J Am Soc Nephrol 2004;15:928-939.

27 Inoue S, Sugitani A, Yamamoto H, Kitada H, Motoyama K, Okabe Y, et al: Effect of synthetic protease inhibitor gabexate mesilate on the attenuation of ischemia/reperfusion injury in canine kidney autotransplantation. Surgery 2005;137:216-224.

28 Jeruc J, Vizjak A, Rozman B, Ferluga D: Immunohistochemical expression of activated caspase-3 as a marker of apoptosis in glomeruli of human lupus nephritis. Am J Kidney Dis 2006;48:410-418.

29 Daemen MA, van 't Veer C, Denecker G, Heemskerk VH, Wolfs TG, Clauss M, et al: Inhibition of apoptosis induced by ischemia-reperfusion prevents inflammation. J Clin Invest 1999;104:541-549.

30 Guo R, Wang Y, Minto AW, Quigg RJ, Cunningham PN: Acute renal failure in endotoxemia is dependent on caspase activation. J Am Soc Nephrol 2004;15:3093-3102.

31 Wan C, Wang C, Liu T, Wang H, Yang Z: Experimental study on the cryopreservation of LLC-PK1 epithelial cells with hypoxic UW solution. J Huazhong Univ Sci Technolog Med Sci 2007;27:426-428.

32 Yin M, Currin RT, Peng XX, Mekeel HE, Schoonhoven R, Lemasters JJ: Carolina rinse solution minimizes kidney injury and improves graft function and survival after prolonged cold ischemia. Transplantation 2002;73:1410-1420. 